\title{
Analisis dan Perancangan Sistem Informasi Manajemen Sumberdaya Manusia dengan Metode Analisis Pieces (Studi Kasus pada PT. Asuransi)
}

\author{
Ridwan Halim
}

Program Magister Teknologi dan Rekayasa, Universitas Gunadarma, Jakarta, Indonesia E-mail: ridwanhalim_feni@yahoo.com

\begin{tabular}{l}
\hline Article Info \\
\hline Article Hist \\
Received: 2021 \\
Revised: 2021 \\
Published: 2021 \\
\\
Keywords: \\
Design; \\
System; \\
Information; \\
Analysis; \\
Pieces.
\end{tabular}

Artikel Info

Sejarah Artikel

Diterima: 2021-07-12

Direvisi: 2021-08-15

Dipublikasi: 2021-09-28

Kata kunci:

Perancangan;

Sistem;

Informasi;

Analisis;

Pieces.

\begin{abstract}
PT Asuransi experienced a rapid growth of business and in line with the increasing of business activity required effective and efficient human resources management. Along with the development of a changing world where life and new technology continue to be developed. This change requires that organizational leaders to be aware of the different types of technology that can improve the effectiveness of an organizational. PT. Insurance is experiencing rapid growth of business and in line with increased business activity required effective and efficient labor management. Along with the development of a changing world where life and new technology continue to be developed. This change requires that organizational leaders be aware of the different types of technology that can improve organizational effectiveness. This research analyzed the old system which applied part of Human Resources of PT Asuransi which still use paper form and filed. Using the analysis of various variable of PIECES methods found the advantages and disadvantages of old systems and designs new systems with scope of menus, processes, databases and interfaces using unified modeling language. From the research that has been done with the questionnaire method and interview the results of research both employees and management believes the existing system this sat is no longer able to support human resource management activities. Accompanied by an analysis of the old system flowchart used in the HR department of PT Asuransi which consider as still paper based procedural methods. The results of this study are expected to be used as reference materials management of PT Asuransi for better human resource management
\end{abstract}

\section{PENDAHULUAN}

Dunia yang terus berubah dimana kehidupan dan teknologi baru terus dikembangkan. Perubahan ini mengharuskan pemimpin organisasi menyadari berbagai jenis teknologi yang dapat meningkatkan efektivitas organisasi, sistem informasi Sumber Daya Manusia (SISDM) telah berkembang secara drastis sejak pertama kali diperkenalkan lebih dari 50 tahun yang lalumereka telah jauh melampaui tujuan awal mereka dalam mengubah catatan kertas menjadi database komputer. Di zaman modern, sistem HR / payroll mampu menangani beberapa fungsi HR yang banyak. Perangkat Lunak SDM sekarang 
penuh dengan fitur dan mandiri, tidak hanya sistem penyimpanan data yang sudah dikenal. Dulu, perusahaan digunakan untuk melacak data di atas kertas dan spreadsheet. Namun, dengan kemajuan teknologi, banyak perusahaan menyadari kebutuhan untuk menerapkan sistem komputerisasi yang lebih canggih, seperti Sistem Informasi Manajemen Sumber Daya Manusia. (Gupta : 2013) Sistem informasi manajemen sumber daya manusia (SISDM) memberikan manajemen data strategis tidak hanya dalam strategi rekrutmen dan retensi, namun juga menggabungkan data SISDM ke dalam strategi perusahaan berskala besar. Data yang dikumpulkan dari SISDM menyediakan manajemen dengan alat pengambilan keputusan.

SISDM dapat memiliki penggunaan yang luas dari selebaran sederhana hingga perhitungan kompleks yang dilakukan dengan mudah. Melalui manajemen SDM yang tepat, perusahaan mampu melakukan perhitungan yang berdampak pada bisnis secara keseluruhan. Peranan Sistem informasi manajemen sumber daya manusia dalam sebuah organisasi pada saat ini dapat membantu sebuah organisasi memaksimalkan sumber daya manusia dan menjaga taraf persaingan di pasar. Pada kebanyakan organisasi yang besar Sistem informasi manajemen sumber daya manusia telah menyediakan teknologi yang menjadi tulang punggung semua fungsi manajemen sumber daya manusia. Dalam peran ini, Sistem informasi manajemen sumber daya manusia memainkan peran penting dalam pengoperasian masing-masing komponen Sistem informasi manajemen sumber daya manusia. Selain itu, dengan mengintegrasikan seluruh proses bisnis, Sistem informasi manajemen sumber daya manusia menyediakan alat kontrol, peramalan, dan perencanaan organisasi yang menggantikan fungsi komputerisasi fungsi SDM yang sederhana.

PT Asuransi merupakan perusahaan asuransi yang bergerak di bidang penyedia layanan asuransi bagi korporasi, nama perusahaan ini memang kurang terdengar di kalangan masyarakat dengan ditandai langkah baru yang tidak pernah dilakukan sebelumnya yaitu mengadakan peluncuran produk ke khalayak, Perusahaan telah memulai beberapa lini produk baru yang bisa dibilang belum terlalu familiar pada periode-periode sebelumnya didukung skala bisnis saat ini yang dapat dikatakan pemain papan atas di industri asuransi umum dan dengan adanya tekanan global dari kantor pusat di Jepang dan kantor-kantor di wilayah Asia- pasifik menjadikan tantangan perusahaan untuk dapat dengan waktu singkat segera menunjukan eksistensi dan kinerjanya. Salah satu bagian dari perencanaan strategis secara konkrit untuk masuk ke pasar yang baru adalah dengan meningkatkan kualitas sumberdaya manusia, dengan meningkatkan professionalisme karyawan dijangka pendek dan dijangka panjang dengan merekrut banyak orang-orang muda dan membentuk tim pengembangan sumber daya manusia.

Saat ini perusahaan menanggung beban operasional yang semakin bertambah namun pertumbuhan perusahaan ada dalam tren yang baik dimana pada tahun buku 2015 untuk pertama kalinya perusahaan membukukan nilai penjualan diatas satu triliun rupiah dan ditahun 2016 tumbuh kembali sebesar 25\% namun masih belum dapat dikatakan sumber daya manusia yang baru sudah berkontribusi secara optimal. Hal inilah yang menjadi tantangan perusahaan untuk tidak hanya dapat mengelola sumber daya manusia agar dapat efektif berkontribusi lebih jauh lagi manajemen berharap pengelolaan sumber daya manusia dapat menghasilkan potensi sumber daya manusia berkualitas yang diharapkan.

Dengan pengelolaan sumber daya manusia di PT Asuransi tidak memiliki suatu sistem baku yang digunakan guna mempermudah pekerjaan dan masih melakukan aktifitas yang tergolong bersifat transaksional dimana peran dan fungsinya dapat dikatakan sebatas administrasi dan berorientasi pada prosedur dan proses. Manajemen berharap divisi sumber daya manusia mampu menunjang kelangsungan usaha perusahaan dengan memberikan gambaran yang konseptual mengenai ketersediaan sumber daya manusia saat ini dan dimasa mendatang. Tentu dengan model pengelolaan transaksional saat ini divisi sumber daya manusia belum dapat memenuhi harapan manajemen.

Dengan adanya permasalahan yang terjadi dan perkembangan teknologi informasi yang terjadi saat ini menimbulkan kebutuhan akan terobosan dan salah satu solusi yang dapat diusulkan adalah perencanaan sistem informasi yang mampu membantu divisi manajemen sumber daya manusia PT Asuransi melakukan pekerjaan saat ini dengan beban pekerjaan yang semakin besar dan juga dapat diandalkan berkontribusi dalam perencanaan strategis khususnya dibidang manajemen SDM perusahaan dimasa depan. Metode untuk merencanakan sebuah sistem informasi ada beberapa 
metode analisis. Metode yang dipilih adalah PIECES karena metode ini dapat mencakup semua kriteria dalam menunjang kelangsungan usaha perusahaan, dari latar belakang yang telah diuraikan maka penelitian ini diberi judul "Analisis dan Perancangan Sistem Informasi Manajemen Sumber Daya Manusia Dengan Menggunakan Metode Analisis Pieces (Studi Kasus Pada PT. Asuransi)"

\section{METODE PENELITIAN}

penelitian ini dibuat dalam gambar alur penelitian yang menjelaskan setiap poin pada gambar alur penelitian dengan populasi dalam penelitian ini berjumlah 543 responden PT. Asuransi yang terbagi dalam beberapa divisi atau bagian kerja, penelitian dilakukan dengan menganalisis system dan prosedur manual / lama dengan penggunaan formulir, Dalam menganalisis data digunakan beberapa alat analisis terutama sistem yang baru yang lebih tepat untuk digunakan dalam rangka menunjang kegiatan organisasi.

\section{HASIL DAN PEMBAHASAN}

\section{Sistem Yang Dibutuhkan}

Berikut disajikan hasil analisis kebutuhan terkait dengan system yang direncanakan.

Tabel 1. System Requiremnt Specification

\begin{tabular}{|c|c|c|c|}
\hline No & Area fungsi & Keterangan & $\begin{array}{c}\text { Priorit } \\
y\end{array}$ \\
\hline 1 & Operasional & & \\
\hline A & $\begin{array}{l}\text { Pencatatan data } \\
\text { pribadi karyawan } \\
\text { dan keluarga }\end{array}$ & $\begin{array}{l}\text { Nama pekerja } \\
\text { beserta tanggungan }\end{array}$ & Tinggi \\
\hline B & $\begin{array}{l}\text { Curriculum vitae } \\
\text { karyawan }\end{array}$ & $\begin{array}{l}\text { Termasuk data } \\
\text { pendidikan, } \\
\text { pelatihan dan } \\
\text { pengalaman kerja }\end{array}$ & Tinggi \\
\hline $\mathrm{C}$ & $\begin{array}{l}\text { Monitor } \\
\text { kehadiran }\end{array}$ & $\begin{array}{l}\text { Automatisasi } \\
\text { laporan kehadiran } \\
\text { terhubung dengan } \\
\text { mesin absensi } \\
\text { disemua unit kerja }\end{array}$ & Tinggi \\
\hline $\mathrm{D}$ & Permohonan cuti & $\begin{array}{l}\text { Melakukan proses } \\
\text { permohonan cuti } \\
\text { dan automatisasi } \\
\text { perhitungan hak dan } \\
\text { sisa cuti }\end{array}$ & Tinggi \\
\hline $\mathrm{E}$ & $\begin{array}{l}\text { Permohonan } \\
\text { dinas luar kota / } \\
\text { luar negeri }\end{array}$ & $\begin{array}{l}\text { Melakukan proses } \\
\text { permohonan dinas } \\
\text { luar kota / luar } \\
\text { negeri }\end{array}$ & Rendah \\
\hline $\mathrm{F}$ & $\begin{array}{l}\text { Pencatatan } \\
\text { keuangan } \\
\text { pengelolaan sdm }\end{array}$ & $\begin{array}{l}\text { Pencatatan } \\
\text { keuangan } \\
\text { pengelolaan sdm } \\
\text { termasuk gaji, } \\
\text { tunjangan, bonus, } \\
\text { insentif, asuransi } \\
\text { kesehatan, }\end{array}$ & Tinggi \\
\hline
\end{tabular}

tunjangan, bpjs

ketenagakerjaan,

bpjs kesehatan,

potongan pajak, potongan koperasi

Proses input target

masing-masing

karyawan serta

G Penilaian kinerja automatisasi

penilaian kinerja

dengan hasil kinerja aktual

Memberikan

peringatan secara

$\begin{array}{llll} & \text { Laporan } & \text { otomatis apabila ada } & \\ \text { H lowongan } & \text { unit kerja yang } & \text { Sedang }\end{array}$

pekerjaan vacant beserta job

description candidat

yang sesuai

Automatisasi

laporan terkait

kesehatan karyawan

Laporan taraf

I kesehatan dan

keselamatan kerja

sesuai data absensi

yang dikumpulkan

Rendah

beserta laporan dari

penyedia asuransi

kesehatan

Membuat rekap dari

semua elemen

Automatisasi

J pelaporan

internal

operasional dalam sebuah dashboard

Tinggi

yang mudah

dimengerti

\begin{tabular}{clll}
\hline 2 & Fungsional & & \\
\hline & & Menjadi portal & \\
K & $\begin{array}{l}\text { Rekrutmen } \\
\text { internal dan } \\
\text { eksternal }\end{array}$ & $\begin{array}{l}\text { informasi lowongan } \\
\text { pekerjaan baik ke } \\
\text { eksternal maupun }\end{array}$ & Sedang \\
& & internal
\end{tabular}
internal

Melakukan proses

seleksi dengan

parameter job

L Seleksi karyawan description dan persyaratan

Tinggi

minimum yang

harus dimiliki

kandidat

\begin{tabular}{|c|c|c|c|}
\hline M & $\begin{array}{l}\text { Penempatan kerja } \\
\text { karyawan }\end{array}$ & $\begin{array}{l}\text { Melakukan seleksi } \\
\text { penempatan sesuai } \\
\text { dengan job } \\
\text { description }\end{array}$ & Tinggi \\
\hline $\mathrm{N}$ & $\begin{array}{l}\text { Promosi } \\
\text { karyawan }\end{array}$ & $\begin{array}{l}\text { Melakukan proses } \\
\text { penilaian serta } \\
\text { penyaringan } \\
\text { karyawan dengan } \\
\text { kriteria nilai kinerja, } \\
\text { masa kerja maupun } \\
\text { variabel lainnya }\end{array}$ & Sedang \\
\hline 0 & $\begin{array}{l}\text { Pencocokan } \\
\text { penugasan kerja }\end{array}$ & $\begin{array}{l}\text { Melakukan seleksi } \\
\text { kedalam data } \\
\text { karywan untuk } \\
\text { penugasan khusus } \\
\text { sesuai dengan } \\
\text { kriteria tugas } \\
\text { dengan cara seleksi } \\
\text { data karyawan yang } \\
\text { sesuai kriteria }\end{array}$ & Sedang \\
\hline
\end{tabular}




\begin{tabular}{|c|c|c|c|}
\hline 3 & Strategic & & \\
\hline $\mathrm{P}$ & $\begin{array}{l}\text { Project training } \\
\text { karyawan }\end{array}$ & $\begin{array}{l}\text { Memberikan laporan } \\
\text { komprehensif } \\
\text { terkait profil serta } \\
\text { kebutuhan pelatihan } \\
\text { dan pengembangan } \\
\text { sdm }\end{array}$ & Sedang \\
\hline Q & $\begin{array}{l}\text { Perencanaan } \\
\text { tenaga kerja }\end{array}$ & $\begin{array}{l}\text { Melakukan } \\
\text { forecasting } \\
\text { kebutuhan sdm } \\
\text { dimasa yang akan } \\
\text { datan }\end{array}$ & Sedang \\
\hline $\mathrm{R}$ & $\begin{array}{l}\text { Pengelolaan dana } \\
\text { pensiun }\end{array}$ & $\begin{array}{l}\text { Mengelola dana } \\
\text { pensiun karyawan } \\
\text { agar operasional } \\
\text { (keuangan) } \\
\text { perusahaan tidak } \\
\text { terganggu }\end{array}$ & Rendah \\
\hline
\end{tabular}

\section{Usulan Sistem Baru}

Dari data yang didapat melalui kuesioner dan wawancara serta ekspektasi yang disampaikan dari pihak manajemen PT Asuransi maka ruang lingkup sistem yang dapat diusulkan dapat diilustrasikan dalam bentuk siklus pada

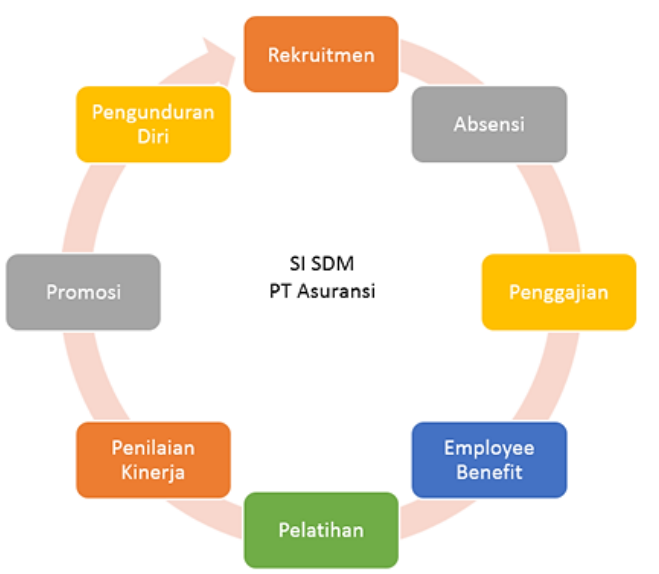

Gambar 1. Ruang lingkup SI SDM PT Asuransi

\section{Analisis Sistem Baru}

Dengan mengacu kepada informasi dari para eksekutif bagian SDM yang mengharapkan fitur sistem pada system requirement specification pada sub bab sebelumnya, pada tabel 4.7 Dapat dianalisis resources data dan parameter yang dapat dikembangkan.

Tabel 2. Analisa Sistem Baru

\begin{tabular}{|c|c|c|}
\hline Modul & Resource data & Parameter \\
\hline Rekruitmen & $\begin{array}{l}\text { 1. Eksternal } \\
\text { 2. Internal }\end{array}$ & $\begin{array}{l}\text { 1. Informasi lowongan } \\
\text { 2. Kualifikasi kandidat } \\
\text { 3. Standarisasi proses } \\
\text { rekrutmen } \\
\text { 4. Penjadwalan proses }\end{array}$ \\
\hline Absensi & $\begin{array}{l}\text { 1. Mesin absen } \\
\text { sidik jari } \\
\text { 2. Informasi cuti, }\end{array}$ & $\begin{array}{l}\text { 1. Jumlah cuti tahunan } \\
\text { 2. Jumlah jam lembur }\end{array}$ \\
\hline
\end{tabular}

sakit, alpa

3. Informasi jam lembur

1. Daftar gaji perkaryawan

2. Perhitungan potongan ketidakhadiran

Penggajian 3. Perhitungan jam lembur

1. Daftar gaji tetap

2. Jumlah hari masuk

3. Jumlah jam lembur

4. Tarif jam lembur

4. Potongan pajak

5. Potongan lainlain

1. Informasi grade Karyawan $\quad$ Penambahan jumlah

\begin{tabular}{|c|c|c|}
\hline $\begin{array}{l}\text { Employee } \\
\text { Benefit }\end{array}$ & $\begin{array}{l}\text { Karyawan } \\
\text { 2. Informasi } \\
\text { Tanggungan } \\
\text { Karyawan } \\
\end{array}$ & $\begin{array}{l}\text { Penambahan jumlah } \\
\text { tanggungan }\end{array}$ \\
\hline Pelatihan & $\begin{array}{l}\text { 1. Informasi grade } \\
\text { Karyawan } \\
\text { 2. Daftar pelatihan }\end{array}$ & $\begin{array}{l}\text { 1. Kategori pelatihan } \\
\text { 2. Penjadwalan } \\
\text { pelatihan } \\
\text { 3. Nilai pelatihan } \\
\text { 4. Sertifikasi pelatihan }\end{array}$ \\
\hline $\begin{array}{l}\text { Penilaian } \\
\text { Kinerja }\end{array}$ & $\begin{array}{l}\text { 1. Goal Setting } \\
\text { Kuantitatif } \\
\text { 2. Goal Setting } \\
\text { Kualitatif } \\
\text { 3. Hasil } \\
\text { pencapaian } \\
\text { kinerja }\end{array}$ & $\begin{array}{l}\text { Kategori pencapaian } \\
\text { kinerja }\end{array}$ \\
\hline Promosi & $\begin{array}{l}\text { 1. Kategori } \\
\text { pencapaian } \\
\text { kinerja } \\
\text { 2. Rekomendasi } \\
\text { atasan } \\
\text { 3. Lulus seleksi }\end{array}$ & $\begin{array}{l}\text { 1. Informasi Lowongan } \\
\text { 2. Kualifikasi kandidat }\end{array}$ \\
\hline $\begin{array}{l}\text { Pengundura } \\
\text { n diri }\end{array}$ & $\begin{array}{l}\text { 1. Alasan } \\
\text { pengunduran } \\
\text { diri } \\
\text { 2. Kritik dan saran }\end{array}$ & $\begin{array}{l}\text { 1. Analisis alasan } \\
\text { 2. Analisis kritik dan } \\
\text { saran }\end{array}$ \\
\hline
\end{tabular}

\section{Perancangan System}

a) Perancangan Proses

Tabel 3. Aktor, use case dan penjelasan Dalam sistem informasi SDM PT Asuransi

\begin{tabular}{|c|c|c|}
\hline Aktor & Use Case & Penjelasan \\
\hline \multirow[t]{3}{*}{ Karyawan } & $\begin{array}{l}\text { Edit data } \\
\text { pribadi }\end{array}$ & $\begin{array}{l}\text { Karyawan melakukan } \\
\text { cek data pribadi yang } \\
\text { tercatat dibagian SDM } \\
\text { pada saat melamar } \\
\text { pekerjaan dan } \\
\text { melakukan update } \\
\text { sesuai informasi terkini } \\
\text { termasuk data } \\
\text { pendidikan dan } \\
\text { pengalaman juga data } \\
\text { tanggungan }\end{array}$ \\
\hline & $\begin{array}{l}\text { Pengajuan izin } \\
\text { dan cuti }\end{array}$ & $\begin{array}{l}\text { Karyawan dapat } \\
\text { mengajukan cuti / izin } \\
\text { dan dapat juga melihat } \\
\text { sisa cuti yang tersedia }\end{array}$ \\
\hline & Resign & $\begin{array}{l}\text { Pengajuan } \\
\text { pengunduran diri } \\
\text { karyawan diajukan } \\
\text { melalui sistem }\end{array}$ \\
\hline
\end{tabular}




\begin{tabular}{|c|c|c|}
\hline & & $\begin{array}{l}\text { sehingga dapat } \\
\text { memberikan notifikasi } \\
\text { kekosongan posisi }\end{array}$ \\
\hline \multirow{3}{*}{ Atasan } & $\begin{array}{l}\text { Penilaian } \\
\text { kinerja }\end{array}$ & $\begin{array}{l}\text { Karyawan dapat } \\
\text { melihat target } \\
\text { pekerjaan yang } \\
\text { diberikan oleh atasan } \\
\text { beserta detail Job } \\
\text { Description }\end{array}$ \\
\hline & Rekomendasi & $\begin{array}{l}\text { Atasan dapat } \\
\text { memberikan } \\
\text { rekomendasi kepada } \\
\text { bawahannya untuk } \\
\text { mutase, promosi, } \\
\text { pendidikan }\end{array}$ \\
\hline & $\begin{array}{l}\text { Update Man } \\
\text { Power } \\
\text { Planning }\end{array}$ & $\begin{array}{l}\text { Masing-masing unit } \\
\text { kerja dapat melakukan } \\
\text { review kinerja } \\
\text { operasional dan } \\
\text { melakukan update } \\
\text { kebutuhan SDM } \\
\text { kebagian SDM }\end{array}$ \\
\hline \multirow{4}{*}{ Staff SDM } & $\begin{array}{l}\text { Payroll } \\
\text { Management }\end{array}$ & $\begin{array}{l}\text { Staff HR melakukan } \\
\text { review laporan absensi }\end{array}$ \\
\hline & $\begin{array}{l}\text { Open } \\
\text { Recruitment }\end{array}$ & $\begin{array}{l}\text { Staff HR membuka } \\
\text { open recruitment ke } \\
\text { internal maupun } \\
\text { external baik untuk } \\
\text { posisi kosong dalam } \\
\text { formasi existing } \\
\text { maupun update man } \\
\text { power planning yang } \\
\text { diisikan oleh masing- } \\
\text { masing atasan ditiap- } \\
\text { tiap unit kerja }\end{array}$ \\
\hline & Cek Kehadiran & $\begin{array}{l}\text { Melakukan } \\
\text { perhitungan kehadiran } \\
\text { dan jam kerja lembur } \\
\text { dari mesin absen }\end{array}$ \\
\hline & Pelatihan & $\begin{array}{l}\text { Bagian SDM dapat } \\
\text { membuat pelatihan } \\
\text { dengan berbagai modul } \\
\text { yang terjadwal dan } \\
\text { menginformasikan } \\
\text { melalui sistem } \\
\end{array}$ \\
\hline $\begin{array}{l}\text { Staff } \\
\text { Keuangan }\end{array}$ & $\begin{array}{l}\text { Pembayaran } \\
\text { gaji }\end{array}$ & $\begin{array}{l}\text { Pembayaran gaji } \\
\text { setelah } \\
\text { memperhitungkan } \\
\text { kehadiran, potongan } \\
\text { item benefit (asuransi, } \\
\text { bpjs), potongan pajak }\end{array}$ \\
\hline \multirow[t]{2}{*}{$\begin{array}{l}\text { Admmin SI } \\
\text { SDM }\end{array}$} & $\begin{array}{l}\text { Setting } \\
\text { authorisasi } \\
\text { User }\end{array}$ & $\begin{array}{l}\text { Admin mengelola } \\
\text { batasan-batasan } \\
\text { masing-masing user } \\
\text { sesuai dengan tugas } \\
\text { dan kewenangannya }\end{array}$ \\
\hline & $\begin{array}{l}\text { Maintainance } \\
\text { sistem }\end{array}$ & $\begin{array}{l}\text { Secara teratur } \\
\text { melakukan } \\
\text { maintanance }\end{array}$ \\
\hline
\end{tabular}

\section{b) Perancangan Database}

Proses perancangan database pada perencanaan sistem ini diawali dengan pembuatan class diagram dari sistem yang direncankan. Gambar 4.19 akan menjelaskan class diagram yang ada pada sistim informasi SDM PT Asuransi yang direncanakan

c) Perancangan Database

Proses perancangan database pada perencanaan sistem ini diawali dengan pembuatan class diagram dari sistem yang direncankan. Gambar 2 akan menjelaskan class diagram yang ada pada sistim informasi SDM PT Asuransi yang direncanakan.

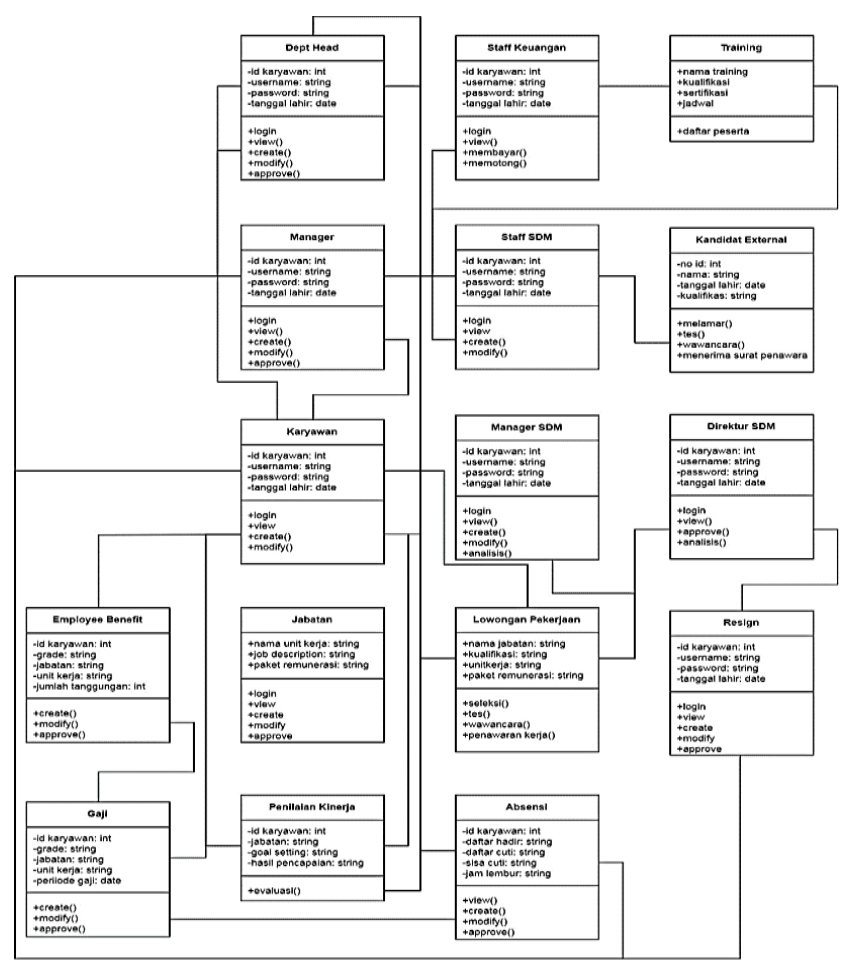

Gambar 2. Class Diagram

d) Perancangan Interface

Rancangan user interface pada sistem yang dirancangkan. Dengan mengacu kepada daftar menu sistem yang telah dibahas sebelumnya, berikut rancangan tampilan user interface pada sistem informasi SDM PT Asuransi.

1. Halaman Login

Pada halaman login karyawan dapat masuk kesistem dengan memasukan ID Karyawan sebagai username dan password yang disediakan bagian SDM.

\section{PT ASURANSI}

SISTEM INFORMASI SUMBER DAYA MANUSIA

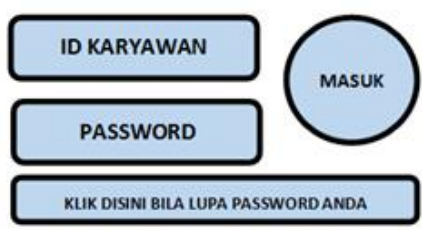

Gambar 3. halaman login 
2. Halaman Home

Akses masing-masing karyawan memiliki batasan berbeda-beda namun secara umum dikategorikan menjadi dua kategori yaitu karyawan level manager kebawah hanya bisa melihat dan melakukan input. Sedangkan pada kategori manager keatas selain melihat dan menginput juga bisa memberikan approval memenuhi undangan interview calon karyawan dari SDM, hingga memberi rekomendasi pada training yang diajukan karyawan.

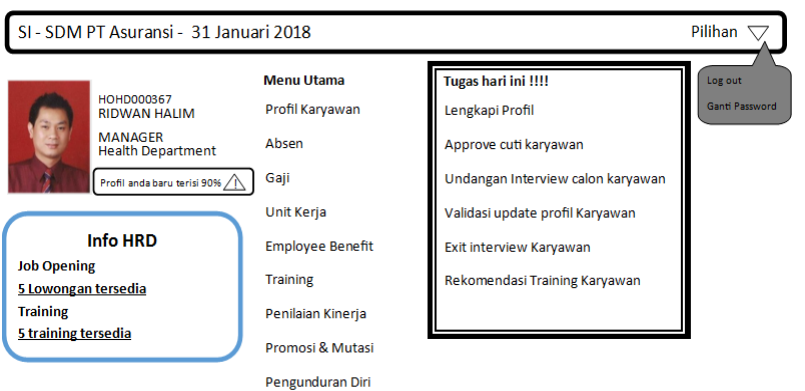

Gambar 4. Home screen user karyawan

3. Halaman Profil Karyawan

Pada halaman ini profil karyawan berupa data pribadi dan data professional pada awalnya akan dimuat oleh sistem namun masing-masing karyawan wajib melakukan update apabila ada perubahan. Lebih jelasnya diilustrasikan pada gambar di bawah ini.
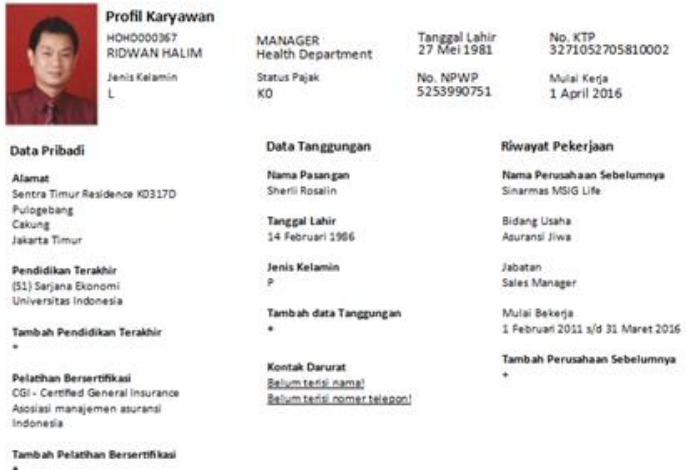

Gambar 5. Halaman profil karyawan

4. Daftar Absensi

Pada halaman ini setiap karyawan dapat melihat daftar absen dan mengajukan cuti tahunan. dan mendapatkan surat keterangan dari dokter atau rumah sakit karyawan dapat mengajukan cuti sakit dengan mengajukan cuti sakit dan melampirkan surat keterangannya dengan cara upload kesistem.
SI - SDM PT Asuransi - 31 Januari 2018

Home

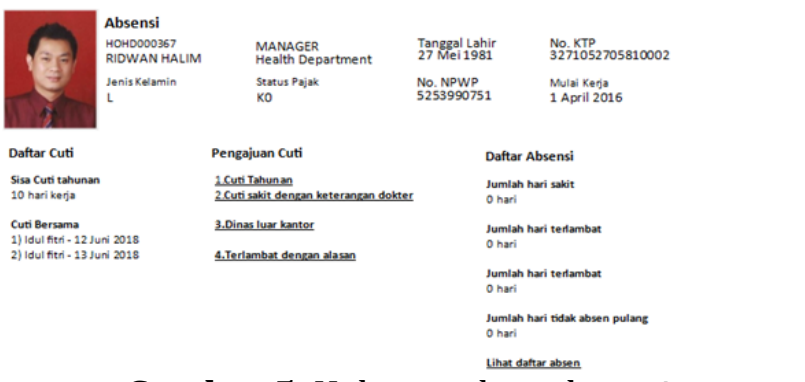

Gambar 5. Halaman data absensi

5. Man Power Planning

Halaman ini hanya dapat diakses oleh user karyawan level manager keatas dimana fungsi dari menu ini adalah mengakselerasi proses rekrutmen kebutuhan tenaga kerja. Diawal tahun setiap manager menginformasikan kebutuhan tenaga kerja masing-masing sesuai dengan target unit kerja.

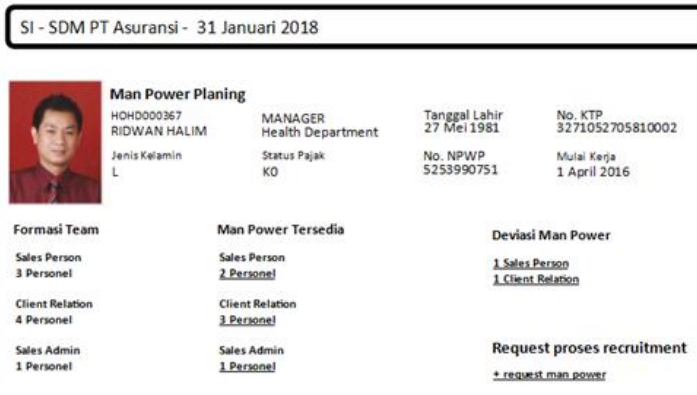

Gambar 6. halaman man power planning

6. Gaji

Pada halaman ini dapat diilustrasikan informasi gaji masing-masing karyawan. Rincian gaji yang diterima karyawan dapat dilihat Pada gambar berikut diilustrasikan halaman employee benefit sebagai berikut. Karyawan dapat melihat detail potongan ataupun tambahan pembayaran gaji dari jam lembur dengan lebih terperinci. Informasi gaji periode sebelumnya juga dapat diakses.

SI - SDM PT Asuransi - 31 Januari 2018 ome
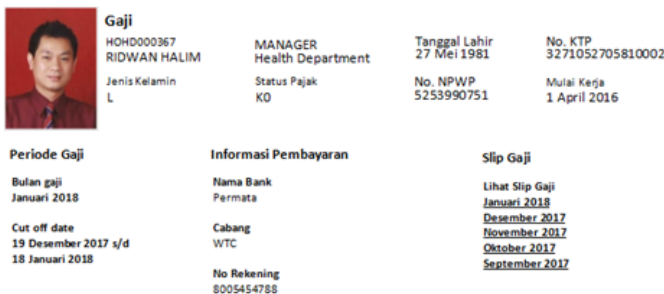

Gambar 7. Halaman Gaji 
7. Employee Benefit

Halaman berikutnya adalah menu employee benefit yang dirancang untuk mempermudah karyawan untuk melihat benefit-benefit tambahan yang disediakan perusahaan.

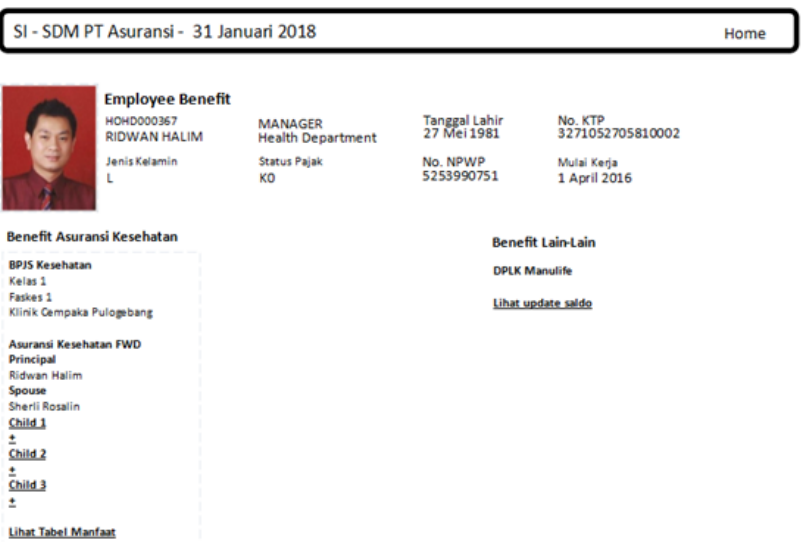

Gambar 8. halaman employee benefit

8. Training \& Job Opening

Bagian SDM dapat menginformasikan adanya Job opening internal dan training melalui sistem.

SI - SDM PT Asuransi - 31 Januari 2018

Home

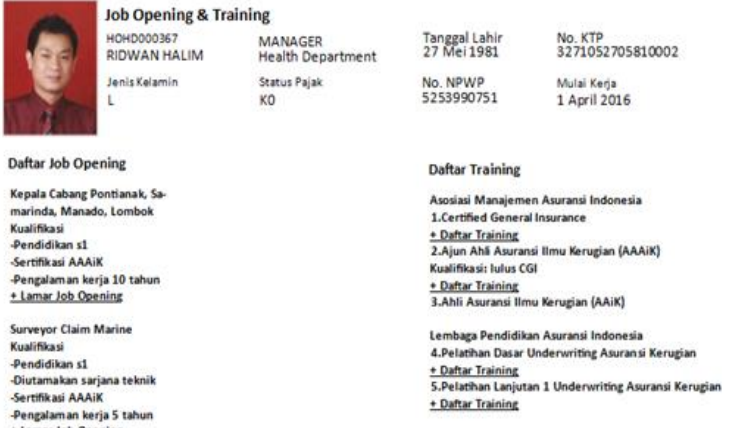

Gambar 9. halaman Job Opening \& Training

9. Penilaian Kinerja

Pada halaman ini setiap karyawan dapat mengisikan goal setting atau target masing-masing diawal tahun dan mengisikan hasil pencapaian pada setiap kuartal atau 3 bulan sekali. Sistem dapat mengkalkulasi deviasi dari pencapaian dengan goal setting yang diisikan informasi ini sangat bermanfaat bagi karyawan maupun atasannya agar target yang dibebankan dapat termonitor dengan baik. Berikut dalam gambar diilustrasikan halaman penilaian kinerja.
SI - SDM PT Asuransi - 31 Januari 2018 Home

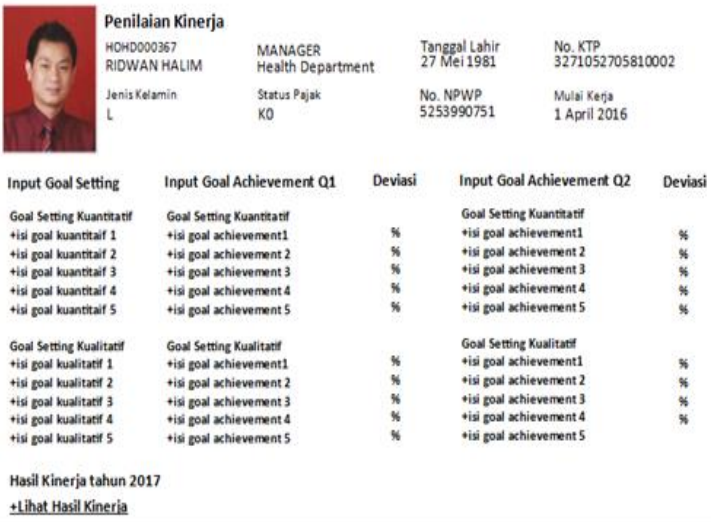

Gambar 10. halaman penilaian kinerja.

10. Pengunduran Diri

Menu ini dirancang untuk dapat menginformasikan kebutuhan tenaga kerja dengan lebih cepat baik kepada para user maupun bagian SDM. Selain dari itu usaha untuk memperkecil tingkat turnover karyawan juga menjadi concern perusahaan dan dengan mengadopsi prosedur manual yang atasan akan ternotifikasi apabila ada karyawan yang mengajukan resign dan perlu rekomendasi atasan satu tingkat diatas atasan langsung untuk memberikan approval pengunduran diri. Sistem juga dapat membantu bagian SDM untuk menganalisis alasan resign dan mendapatkan feedback kritik dan saran. Untuk menu fungsi resign ini diilustrasikan pada gambar di bawah ini:

SI - SDM PT Asuransi - 31 Januari $2018 \quad$ Home

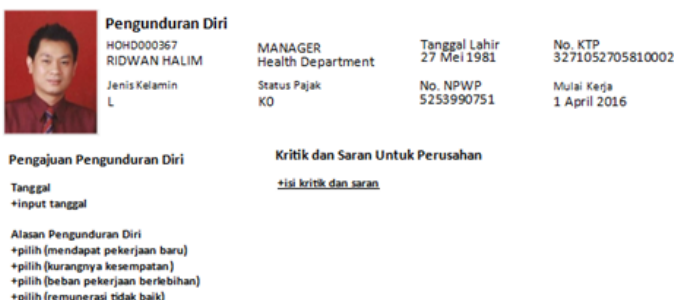

Gambar 11. halaman pengunduran diri

\section{SIMPULAN DAN SARAN}

\section{A. Simpulan}

Dari penelitian yang telah dilakukan menghasilkan analisis sistem lama yang digunakan bagian SDM PT Asuransi yang bersifat prosedural manual dengan paper based dan dirancang sistem informasi sumber daya manusia untuk menunjang aktifitas manajaemen sumber daya manusia di PT Asuransi. 
Analisis SISDM dengan metode PIECES dilakukan dengan pengembangan variablevariabel performance, information, economic, control, efficiency dan service dalam dimensidimensi yang menjadi pertimbangan utama dalam penilaian aktifitas manajemen sumber daya manusia di PT Asuransi. Dari dimensidimensi yang ada dikembangkan kembali menjadi indikator-indikator yang mudah dipahami para responden. Dalam melakukan analisis sistem yang lama indikator-indikator ini juga diaplikasikan untuk melakukan penilaian kelebihan dan kekurangannya. Pengumpulan data dengan metode antara lain; kuesioner kepada responden karyawan, wawancara kepada para eksekutif dibidang SDM, analisis flow chart prosedur sistem lama dan pencatatan system requirement specification

Perancangan SISDM yang dilakukan dengan merancang proses, database, dan merancang interface. Perancangan proses dengan menggunakan UML meliputi diagram use case dan sequence. Perancangan database menghasilkan 16 tabel. Perancangan menu meliputi Log in, home, profil karyawan, daftar absensi, man power planning, gaji, employee benefit, training dan job opening, penilaian kinerja dan pengunduran diri

\section{B. Saran}

Pada akhirnya dengan mempertimbangkan pertumbuhan perusahaan, persaingan bisnis dan kemajuan berkelanjutan penulis menyarankan agar SISDM yang direncanakan ini dapat dikembangkan oleh PT Asuransi.

\section{DAFTAR RUJUKAN}

Arikunto, Suharsimi, (2014) Prosedur Penelitian, Suatu Pendekatan Praktik. Cetakan ke lima belas. Jakarta: Rineka Cipta

Dede Andi, Muhamad Abid, Denok Sunarsi, \& Irfan Rizka Akbar. (2021). Implementasi Pendidikan Karakter Melalui Nilai-nilai Kearifan Lokal di Mts Darul Huda Kp. Cimuncang Kabupaten - Tasikmalaya. JIIP Jurnal Ilmiah Ilmu Pendidikan, 4(3), 149153. Retrieved from http://jiip.stkipyapisdompu.ac.id/jiip/inde x.php/IIIP/article/view/227

Gupta, Barkha (2013) Human Resource Information System (HRIS): Important. Element of Current Scenario. www.iosjournals.org. e-ISSN: 2278-487X, pISSN: 2319-7668. Volume 13, Issue 6

Hangraeni, Dewi. (2012) Manajemen Sumber Daya Manusia. Cetakan kesatu. Jakarta: Lembaga Penerbit Fakultas Ekonomi Universitas Indonesia

Karikari, A. F, Boateng, P.A. and Ocansey, E. O. N. D. (2015) The Role of Human Resource Information System in the Process of Manpower Activities. American Journal of Industrial and Business Management Vol.5 No.6

Linda Suprihatin, \& Denok Sunarsi. (2021). Pengaruh Kepemimpinan Transaksional dan Lingkungan Kerja Terhadap Kinerja Pegawai di Pusat Pendidikan dan Pelatihan Pegawai Kementerian Pendidikan dan Kebudayaan. JIIP - Jurnal Ilmiah Ilmu Pendidikan, 4(1), 78-86. Retrieved from http://jiip.stkipyapisdompu.ac.id/jiip/inde x.php/IIIP/article/view/207

Marakas, G.M and O'brien J.A. (2017) Pengantar Sistem Informasi. Edisi 16. Jakarta: Penerbit Salemba Empat

Nawawi, Hadari. (2015). Perencanaan SDM Untuk Organisasi Profit yang Kompetitif. Cetakan keenam. Yogyakarta: Gadjah Mada Iniversity Press

Rohmat, taufiq, sistem informasi manajemen, konsep dasar, analisi dan metode pengembangan, 2013

Sadiq, U., Khan, A.F., and Ikhlaq, K. (2012) The Impact of Information Systems on the Performance of Human Resources Department. jbsq.org/wpcontent/uploads/2012/.../JBSQ_June2012_6. pdf.

Sedarmayanti. (2017) Perencanaan dan Pengembangan SDM Untuk Meningkatkan Kompetensi, Kinerja, dan Produktivitas Kerja. Bandung: Refika Aditama

Subagyo, Joko (2015). Metode Penelitian dalam Teori dan Praktik. Jakarta: Rineka Cipta

Sudaryono. (2015). Metodologi Riset dibidang TI. Yogyakarta: Penerbit Andi

Taufiq, Rohmat (2013) Sistem Informasi Manajemen Konsep Dasar Analisis dan 
JIIP-Jurnal Ilmiah Ilmu Pendidikan (2614-8854) Volume 4, Nomor 5, September 2021 (374-382)

Pengembangan. Edisi Pertama. Yogyakarta: Yani, H.M. (2012). Manajemen Sumber Daya Graha Ilmu Manusia. Jakarta: Mitra Wacana Media 